\title{
Application of air energy heat pump in brood production of closed yellow-feathered chicken house
}

\author{
Hu Chenming ${ }^{1,2, \text { I }}$, Pen Han ${ }^{1,2}$, Yang $\mathrm{Li}^{1,2}$, Yang Chaowu ${ }^{1,2}$, Xiong Xia ${ }^{2}$, Song Xiaoyan ${ }^{2}$, Yu Chunlin ${ }^{1,2}$, Zhang Zengrong ${ }^{1,2}$, \\ Qiu Mohan ${ }^{1,2}$, Xia Bo ${ }^{1}$, Chen Jialei ${ }^{2}$, Du Longhuan ${ }^{3 *}$ \\ ${ }^{1}$ Sichuan Animal Science Academy, Chengdu, Sichuan, China \\ ${ }^{2}$ Animal Breeding and Genetics Key Laboratory of Sichuan Province, Chengdu, Sichuan, China \\ ${ }^{3}$ College of Architecture and Environment, Sichuan University, Chengdu, Sichuan, China
}

\begin{abstract}
The aim of the study was to compere the effects of using air energy heat pump, flue heating and water heating as brood heating system on brood production of yellow-feathered broilers. In the experiment, three heating methods were used to heat chicks, and the parameters such as heating time, temperature uniformity, concentration of poisonous and harmful gases in the house, chick weight gain, mortality rate and production benefit were compered and analyzed. The results showed as follows: 1 . There was no significant difference in $\mathrm{NH} 3$ and $\mathrm{H} 2 \mathrm{~S}$ concentration among the three groups $(\mathrm{P}>0.05)$. The $\mathrm{CO} 2$ concentration in the flue group was significantly higher than that in the other two groups $(\mathrm{P}<0.01)$, and there was no significant difference in $\mathrm{CO} 2$ concentration between the other two groups $(\mathrm{P}>0.05)$. 2. The body weight of chickens in the flue group at 30 days of age was the lowest, which was significantly different from that in the other two groups $(\mathrm{P}<0.01)$; The air energy heat pump group had significant difference with coal fired boiler group ( $\mathrm{P}$ $<0.05$ ), the uniformity and survival rate of flue group were the lowest, and the air energy heat pump group had the best; 3. The temperature rise of honeycomb flue was the slowest, the temperature distribution uniformity was the worst, and the cost was the highest; The heating rate of coal-fired boiler was faster than that of flue, and the temperature distribution uniformity was better, and the cost was lower. The heating rate of air energy heat pump was the fastest, and the temperature distribution uniformity was better, and the operating cost was the lowest. 4. The air energy heat pump group has higher investment in the early stage, better use effect, better production performance of brood, long service life and lower brood cost.
\end{abstract}

\section{Introduction}

Yellow-feathered broiler industry was a successful representative of the development of China's agricultural industry, and broiler brooding was a particularly important link in the whole breeding process of yellow-feathered broiler [1].

Air energy heat pump was the use of heat exchange with air to generate heat energy, and could transfer heat energy to water supply, to achieve the purpose of heating. The air energy heat pump has been widely used in the human environment, but it has not been reported in the production of yellow-feathered broilers.

The temperature of broilers affects the health of broilers, and then affects the breeding and commercial production of yellow-feathered broilers. At present, honeycomb flue heating was the main heating method for yellow-feathered broilers, and a small number of farms with a certain scale begin to use coal-fired boiler plumbing heating. Due to the special needs of heat preservation for breeding chicks, the closing time was longer. The heating of honeycomb flue for a long time will reduce the humidity in the house, resulting in larger

*Corresponding author: Du Longhuan: longhuan_du@163.com

iAuthor: huchenming@126.com dust, and artificial humidification was needed. Coal-fired plumbing, although it could solve part of the problem of flue heating, but like flue heating, people need to be on duty for a long time, the labor cost was high, and the temperature in the house was difficult to stabilize. With more stringent environmental requirements, some regions were also facing the problem of banning coal burning, so it was imperative to find a new way of heating.

In order to solve the existing problems of broilers heating, we use air energy heat pump, desulfurized honeycomb coal flue heating and coal-fired boiler heating to do a comparative study, to provide some reference for broilers production.

\section{2 material}

\subsection{Experimental animals}

In order to promote the application of the test results, we selected 799 progenitor chicks from Sichuan Daheng Poultry Breeding Co., Ltd. The Daheng 799 accessory system was approved by the state in 2021 and has been promoted in 20 provinces and cities across China. 


\subsection{Main instruments}

GT2000 multifunctional compound gas analyzer, purchased from Korno Electronic Technology Co., Ltd.; TSI9545 digital tester, purchased from TSI Corporation, USA.

\section{Design and method}

\subsection{Test methods}

A total of 15000 chickens of 799 were divided into three large groups with 5000 chickens in each group and numbered as 1, 2 and 3. Feeding experiments were carried out in three brood houses with the same building structure. The feeding methods were the same except for the different heating methods.

In the first group, flue heating method was used [2], desulfurized honeycomb coal was used as fuel, and a total of ten coal feeding holes were set in the house (Fig. 1). The flue was red brick material with a thickness of 6 $\mathrm{cm}$. The second group adopts water circulation hot air heating method, using coal as fuel, boiler water storage capacity of $1 \mathrm{t}$, there were ten heating auxiliary machines in the house, and the installation location of auxiliary machines was the same as that of the coal feeding hole (Figure 2); The third group adopts an air energy heat pump with a boiler storage capacity of $1 \mathrm{t}$. There were 10 heating auxiliary machines in the house, and the installation location of the auxiliary machines was consistent with that of the coal feeding hole (Figure 2).

In winter, the whole day need to heat, energy consumption was the largest, the test results were the most accurate. The ventilation fan at the back end was only opened for 3 minutes after each measurement of toxic and harmful gases.

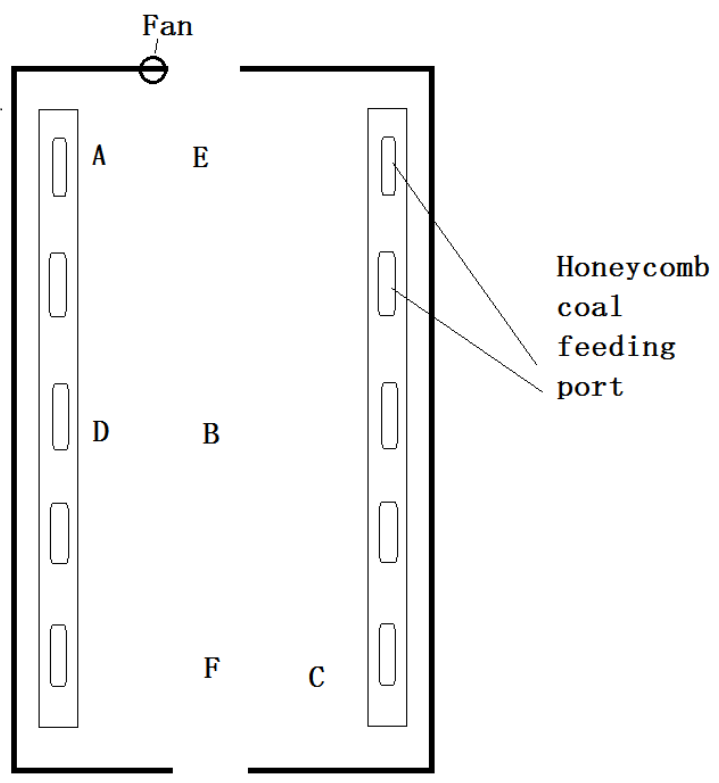

Fig. 1 Schematic diagram of flue heating layout

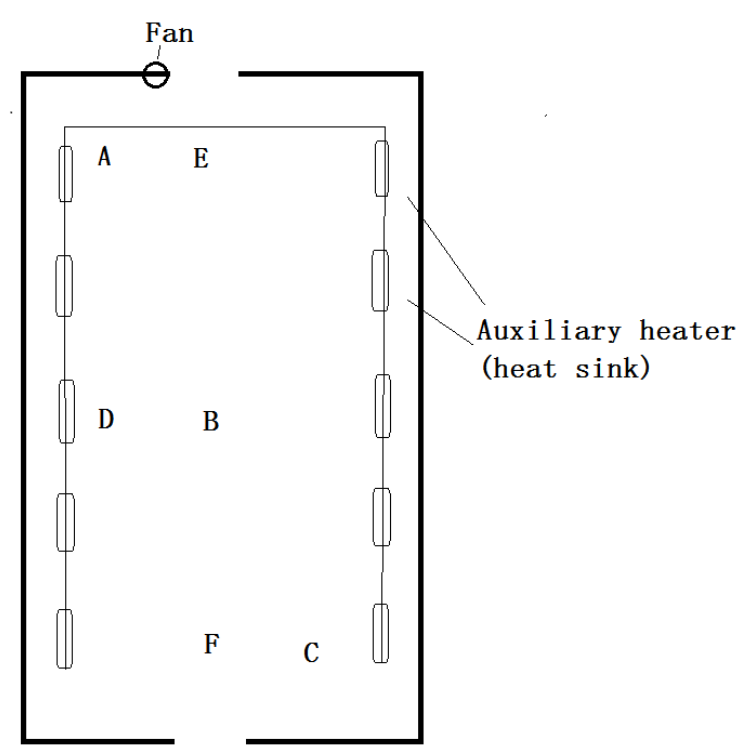

Fig. 2 Hot air heating layout of water cycle

\subsection{Data determination}

\subsubsection{Temperature requirements at brood stage}

The requirements of brood temperature at different age were showed in Table 1.

Table 1 Test brood temperature

\begin{tabular}{|c|c|}
\hline Day age $/ \mathrm{d}$ & temperature $/{ }^{\circ} \mathrm{C}$ \\
\hline $0 \sim 3$ & 36 \\
\hline $4 \sim 7$ & 32 \\
\hline $8 \sim 15$ & 30 \\
\hline $16 \sim 30$ & 25 \\
\hline
\end{tabular}

\subsubsection{Determination method}

During the experiment, the temperature, $\mathrm{NH} 3, \mathrm{H} 2 \mathrm{~S}$ and $\mathrm{CO} 2$ concentration in the house were measured at 6 points in each brood house, and the data were numbered A, B, C, D, E and F (Figure 1 and 2). Point A and C were temperature measurement points of the heat source; D was the temperature measurement point of the first group of cages on the left; B, E and F were temperature measurement points of the middle passage. Point $\mathrm{E}$ was the normally closed back door, and point $F$ was the normally open front door. The mean values of $\mathrm{B}, \mathrm{D}, \mathrm{E}$ and $\mathrm{F}$ were the brood temperatures in the house.

The experiment lasted for 4 times, and the measurement time was 1:00 PM on the same day. At the end of the experiment period, $10 \%$ of samples from each group were weighed, and the live body weight (30 days of age), evenness and mortality rate of broilers in each group were compered and analyzed.

During the test, clean up chicken manure once every 3 days. When the time of cleaning manure coincides with the measurement time, postpone cleaning manure for 1 day to facilitate the measurement of toxic and harmful 
gas concentration.

\subsection{Statistical analysis of data}

Body weight at 30 days of age $=$ total weight $\div$ number of samples;

The total weight of the sample $=$ the sum of the weight of the sampled individuals;

Survival rate $=$ total number at 30 days of age $\div$ total number at 1 day of age;

All the data were processed by Excel, and the single factor $\mathrm{T}$ test was carried out by SPSS to analyze the significouldce of the difference.

\section{Results and analysis}

\subsection{Comparison of heating speed}

Comparison of heating rates of the three heating methods was showed in Table 2.

Table 2 Comparison of heating duration of different test groups

\begin{tabular}{|c|c|c|}
\hline & $25^{\circ} \mathrm{C}$ & $36^{\circ} \mathrm{C}$ \\
\hline 1 & 3.2 & 8.0 \\
\hline 2 & 2.1 & 4.0 \\
\hline 3 & 1.2 & 2.1 \\
\hline
\end{tabular}

As could be seen from Table 2, flue heating was the slowest, water circulation heating of coal-fired boilers was faster than flue heating, and air energy heat pump has the fastest heating speed.

\subsection{Comparison of temperature uniformity in brood house}

For the determination of temperature measurement point $\mathrm{D}$ brood standard temperature, when the measured temperature measurement point $\mathrm{D}$ reaches the temperature of the corresponding day age requirements, meet the requirements as inner environment, and to evaluate other measurement point temperature uniformity, the measurement point B, D, E, F points of the average temperature for inner actually reached temperature (table $3,4)$.

Table 3 Temperature distribution table in autumn and winter

\begin{tabular}{|c|c|c|c|c|c|c|}
\hline \multicolumn{2}{|c|}{} & $\mathrm{B}$ & $\mathrm{D}$ & $\mathrm{E}$ & $\mathrm{F}$ & Average \\
\hline \multirow{4}{*}{1} & $3 / \mathrm{d}$ & $32.8^{\mathrm{C}} \pm 0.4$ & $36.2^{\mathrm{A}} \pm 0.2$ & $32.6^{\mathrm{C}} \pm 0.2$ & $31.2^{\mathrm{C}} \pm 0.2$ & $33.2^{\mathrm{C}} \pm 2.1$ \\
\cline { 2 - 7 } & $7 / \mathrm{d}$ & $30.3^{\mathrm{a}} \pm 0.4$ & $33.1^{\mathrm{A}} \pm 0.2$ & $29.2^{\mathrm{C}} \pm 0.2$ & $29.3^{\mathrm{b}} \pm 0.2$ & $30.5^{\mathrm{Ab}} \pm 1.8$ \\
\cline { 2 - 7 } & $15 / \mathrm{d}$ & $28.4^{\mathrm{C}} \pm 0.4$ & $30.7^{\mathrm{a}} \pm 0.3$ & $32.8^{\mathrm{A}} \pm 0.2$ & $26.1^{\mathrm{b}} \pm 0.2$ & $29.5^{\mathrm{Ab}} \pm 2.9$ \\
\cline { 2 - 7 } & $30 / \mathrm{d}$ & $22.1^{\mathrm{C}} \pm 0.4$ & $25.7^{\mathrm{a}} \pm 0.3$ & $26.3^{\mathrm{a}} \pm 0.2$ & $24.3^{\mathrm{a}} \pm 0.2$ & $24.6^{\mathrm{Ab}} \pm 1.9$ \\
\hline \multirow{4}{*}{2} & $3 / \mathrm{d}$ & $35.6^{\mathrm{A}} \pm 0.3$ & $36.3^{\mathrm{A}} \pm 0.3$ & $39.5^{\mathrm{A}} \pm 0.2$ & $34.1^{\mathrm{AB}_{0}} \pm 0.2$ & $36.4^{\mathrm{AB}} \pm 2.3$ \\
\cline { 2 - 7 } & $7 / \mathrm{d}$ & $32.1^{\mathrm{A}} \pm 0.4$ & $33.2^{\mathrm{A}} \pm 0.3$ & $32.4^{\mathrm{A}} \pm 0.2$ & $31.5^{\mathrm{aB}} \pm 0.2$ & $32.3^{\mathrm{AB}} \pm 0.7$ \\
\cline { 2 - 7 } & $15 / \mathrm{d}$ & $29.8^{\mathrm{A}} \pm 0.3$ & $30.5^{\mathrm{a}} \pm 0.3$ & $33.2^{\mathrm{A}} \pm 0.3$ & $26.5^{\mathrm{aB}} \pm 0.3$ & $30.0^{\mathrm{AB}} \pm 2.8$ \\
\cline { 2 - 7 } & $30 / \mathrm{d}$ & $25.1^{\mathrm{A}} \pm 0.3$ & $27.2^{\mathrm{A}} \pm 0.2$ & $26.6^{\mathrm{A}} \pm 0.2$ & $23.2^{\mathrm{A}} \pm 0.3$ & $25.5^{\mathrm{A}} \pm 1.8$ \\
\hline \multirow{4}{*}{3} & $3 / \mathrm{d}$ & $35.8^{\mathrm{AB}} \pm 0.2$ & $36.5^{\mathrm{A}} \pm 0.2$ & $38.7^{\mathrm{AB}} \pm 0.2$ & $34.5^{\mathrm{A}} \pm 0.3$ & $36.4^{\mathrm{A}} \pm 1.8$ \\
\cline { 2 - 7 } & $7 / \mathrm{d}$ & $32.3^{\mathrm{A}} \pm 0.2$ & $33.5^{\mathrm{a}} \pm 0.2$ & $32.5^{\mathrm{AB}} \pm 0.2$ & $32.9^{\mathrm{A}} \pm 0.3$ & $32.8^{\mathrm{A}} \pm 0.5$ \\
\cline { 2 - 7 } & $15 / \mathrm{d}$ & $29.2^{\mathrm{AB}} \pm 0.3$ & $30.4^{\mathrm{A}} \pm 0.3$ & $31.4^{\mathrm{A}} \pm 0.3$ & $27.8^{\mathrm{A}} \pm 0.3$ & $29.7^{\mathrm{A}} \pm 1.6$ \\
\cline { 2 - 7 } & $30 / \mathrm{d}$ & $24.2^{\mathrm{AB}} \pm 0.2$ & $25.1^{\mathrm{a}} \pm 0.2$ & $24.1^{\mathrm{a}} \pm 0.2$ & $25.1^{\mathrm{A}} \pm 0.2$ & $24.6^{\mathrm{AB}} \pm 0.6$ \\
\hline
\end{tabular}

Note: Among different groups, the same age and the same measurement point, the same capital letters indicated no significant difference $(\mathrm{P}>0.05)$; The same letters represented significant difference $(\mathrm{P}<0.05)$, while different letters represented extremely significant difference $(\mathrm{P}<0.01)$.

As could be seen from Table 3, at the same age, the uniformity of heating temperature of flue in autumn and winter was poor. At the age of 3 days, the difference was extremely significant $(\mathrm{P}<0.01)$; at the age of 7 days, 15 days and 30 days, the difference was significant $(\mathrm{P}<$ 0.05). The temperature uniformity of the other two heating modes was better, and there was no significant difference between the two groups at the same age $(\mathrm{P}>$ 0.05).

\subsection{Comparison of concentrations of toxic and harmful gases in different locations}

During the test, the four toxic and harmful gas measurements were showed in Table 4 and Table 5 below.

Table 4 The first and second measurements of toxic and harmful gases $\mathrm{mg} / \mathrm{m}^{3}$

\begin{tabular}{|c|c|c|c|c|c|c|}
\hline & \multicolumn{3}{|c|}{1} & \multicolumn{3}{c|}{2} \\
\cline { 2 - 6 } & $\mathrm{NH}_{3}$ & $\mathrm{H}_{2} \mathrm{~S}$ & $\mathrm{CO}_{2}$ & $\mathrm{NH}_{3}$ & $\mathrm{H}_{2} \mathrm{~S}$ & $\mathrm{CO}_{2}$ \\
\hline 1 & $3.11^{\mathrm{A}} \pm 0.32$ & $0.13^{\mathrm{A}} \pm 0.08$ & $3882^{\mathrm{A}} \pm 382$ & $2.75^{\mathrm{A}} \pm 0.37$ & $0.11^{\mathrm{A}} \pm 0.11$ & $3112^{\mathrm{A}} \pm 323$ \\
\hline 2 & $2.92^{\mathrm{A}} \pm 0.31$ & $0.13^{\mathrm{A}} \pm 0.07$ & $2556^{\mathrm{B}} \pm 421$ & $2.68^{\mathrm{A}} \pm 0.23$ & $0.15^{\mathrm{A}} \pm 0.08$ & $2311 \pm 336$ \\
\hline
\end{tabular}




\begin{tabular}{|c|c|c|c|c|c|c|}
\hline 3 & $3.02^{\mathrm{A}} \pm 0.19$ & $0.12^{\mathrm{A}} \pm 0.05$ & $2414^{\mathrm{B}} \pm 395$ & $2.66^{\mathrm{A}} \pm 0.40$ & $0.17^{\mathrm{A}} \pm 0.08$ & $2498^{\mathrm{B}} \pm 401$ \\
\hline
\end{tabular}

Note: In the same column, the same capital letters mean no significant difference $(\mathrm{P}>0.05)$; The difference between different letters was very significant $(\mathrm{P}<0.01)$.

Table 5 The third and fourth measurements of toxic and harmful gases $\mathrm{mg} / \mathrm{m}^{3}$

\begin{tabular}{|c|c|c|c|c|c|c|}
\hline & \multicolumn{3}{|c|}{3} & \multicolumn{3}{|c|}{4} \\
\hline & $\mathrm{NH}_{3}$ & $\mathrm{H}_{2} \mathrm{~S}$ & $\mathrm{CO}_{2}$ & $\mathrm{NH}_{3}$ & $\mathrm{H}_{2} \mathrm{~S}$ & $\mathrm{CO}_{2}$ \\
\hline 1 & $2.31 \pm 0.49$ & $0.12 \pm 0.01$ & $2211 \pm 289$ & $1.87 \pm 0.47$ & $0.12 \pm 0.07$ & $1831 \pm 291$ \\
\hline 2 & $2.33 \pm 0.34$ & $0.12 \pm 0.05$ & $2054 \pm 319$ & $2.12 \pm 0.41$ & $0.15 \pm 0.03$ & $1956 \pm 321$ \\
\hline 3 & $2.41 \pm 0.50$ & $0.15 \pm 0.03$ & $2110 \pm 307$ & $2.01 \pm 0.50$ & $0.13 \pm 0.02$ & $1921 \pm 400$ \\
\hline
\end{tabular}

As could be seen from Tables 4 and 5, there was no significant difference in $\mathrm{NH} 3$ and $\mathrm{H} 2 \mathrm{~S}$ concentrations in the three heat groups $(\mathrm{P}>0.05)$. The carbon dioxide concentration in flue group was significantly higher than that in the other two groups in the first two measurements $(\mathrm{P}<0.01)$, but there was no significant difference in carbon dioxide concentration between the other two groups $(\mathrm{P}>0.05)$. In the last two measurements, there was no significant difference in carbon dioxide concentration between the three groups $(\mathrm{P}>0.05)$.

\subsection{Comparison of production performance}

The production performance at the end of the test was showed in Table 6 below.

Table 6 Statistical table of production performance

\begin{tabular}{|c|c|c|c|c|}
\hline & $\begin{array}{c}\text { Weight at 30 days } \\
\text { of age }(\mathrm{g})\end{array}$ & Uniformity (\%) & $\begin{array}{c}\text { Anal occlusion rate at } \\
\text { 0-7 days of age (\%) }\end{array}$ & Survival rate (\%) \\
\hline 1 & $515 \pm 51^{\mathrm{C}}$ & 0.75 & 9 & 95.3 \\
\hline 2 & $535 \pm 34^{\mathrm{aB}}$ & 0.84 & 7 & 97.8 \\
\hline 3 & $555 \pm 39^{\mathrm{A}}$ & 0.88 & 3 & 98.7 \\
\hline
\end{tabular}

Note: he same capital letters indicated no significant difference $(\mathrm{P}>0.05)$. The same letters represented significant difference $(\mathrm{P}<$ $0.05)$, while different letters represented extremely significant difference $(P<0.01)$.

As could be seen from Table 6, the body weight of chickens in the flue group at 30 days of age was lighter than that in the other two groups, and the difference was extremely significant $(\mathrm{P}<0.01)$. There was significant difference between the air-energy heat pump group and the coal-fired boiler group $(\mathrm{P}<0.05)$. The uniformity and survival rate of flue group were the lowest, and the

Table 7 Cost comparison table

\begin{tabular}{|c|c|c|c|c|c|c|}
\hline & & & & & & \\
Consumption could & The unit price/yuan & $\begin{array}{c}\text { Labor cost/yuan / } \\
\text { month }\end{array}$ & Equipment input/yuan & $\begin{array}{c}\text { Equipment } \\
\text { service } \\
\text { life/year }\end{array}$ & Total/yuan \\
\hline 1 & 12124 & 0.88 & 3500 & 10500 & 10 & 15219.1 \\
\hline 2 & $10.2 \mathrm{t}$ & 870 & 3500 & 21000 & 7 & 15374.0 \\
\hline 3 & $3589 \mathrm{Kw}$ & 0.5 & 0 & 90000 & 15 & 7794.5 \\
\hline
\end{tabular}

As could be seen from Table 7, the air energy heat pump mode has the lowest cost, without additional labor costs, and the flue heating mode has the highest cost. weight, evenness and survival rate of air energy heat pump group were the best.

\subsection{Comparison of use costs}

Input costs were showed in Table 7 below. 


\section{Discuss}

\subsection{Analysis of indoor environment results}

\subsection{1 temperature}

The heating method of flue group was mainly by natural heat emission. Coal-fired boiler and air could heat pump hot water temperature inside the boiler outside first to the required temperature, then by the circulation pump hot water into the inner hot compress machine, after on hot compress machine to the inner blow out hot air to heat, hot compress machine in 24 hours of the water in the pipe, and the heat source temperature was lower than the flue group asked, boiler thermal insulation effect was better also, so the heat efficiency was higher than the flue. In addition, in the heating mode of air energy heat pump [3], the air was mainly compressed by an electrically driven air compressor and dissipated by a special coolant. Its working principle was similar to air conditioning, and its own thermal efficiency was higher than that of coal, so the air energy heat pump heats the water in the furnace faster than that of coal [4].

\subsubsection{Toxic and harmful gases}

Wang Xiaoning and Zheng Shuli et al. found that the concentration of $\mathrm{NH} 3$ and $\mathrm{H} 2 \mathrm{~S}$ was related to chicken manure cleaning and ventilation frequency [5-6] when studying the regularity of toxic and harmful gases in the closed house. The number of chickens reared in the three experimental houses was the same, and the frequency of feces cleaning and ventilation were also the same. Therefore, there was no significant difference in the concentrations of $\mathrm{NH} 3$ and $\mathrm{H} 2 \mathrm{~S}$ in the house between the groups, which was consistent with their results.

In the flue heating group, $\mathrm{CO}$ may be produced due to incomplete combustion of honeycomb coal in the house, and the $\mathrm{CO}$ content in the air could reach $0.1 \% \sim 0.2 \%$, if inhaled a small amount, it could cause poisoning [7-8].

In order to strengthen the brood inner insulation, brood were usually relatively closed environment, in addition to the normal metabolism of chicken produces $\mathrm{CO} 2$, it will consume more in inner combustion honeycomb briquet to inner oxygen, to produce more $\mathrm{CO} 2$, so the highest flue group inner $\mathrm{CO} 2$ concentrations. The other two groups also had lower $\mathrm{CO} 2$ in the house because they were heated outside the house.

\subsection{Production benefit analysis}

\subsubsection{Production performance}

When the flue was heated, the uniformity of temperature in the house was poor, and the uneven temperature has a great influence on the intake of food, drinking water and yolk absorption of chicks [9]. During the experiment, some weak chickens died gradually after 7 days of age, and the weight gain rate of the remaining weak chickens was slower in the later period, which reduced the population survival rate and evenness. Poor evenness will also affect the weight of the brood population.

\subsubsection{Production cost}

With the intensification of environmental protection work, the environmental protection requirements for coal mining were getting higher and higher, and the labor cost and transportation cost were rising one after another, leading to the rise of coal burning costs for breeding farms. At the same time, the heating of honeycomb coal or coal-fired boiler heating, both need two people 24 hours in turn on duty. The air energy heat pump boiler heating was automatically controlled by the computer module, and the external alarm device, daily machine work only need to read the meter and simple operation record, the workload was small, the original field electrician could work part-time, without extra pay. Although the initial investment of air energy heat pump equipment was high, the actual operating cost was lower.

\section{6 conclusion}

The air energy heat pump heating mode, although the early hardwwere investment was high, but the equipment heating fast, internal environment control was better, the chick weight was the highest, the economic benefit was the best, and the operation cost was the lowest, and will not produce other harm to the staff and the environment, for a certain scale of brood farm was a better brood heating mode.

As the use of coal-fired boilers has been largely banned, air-energy heat pumps could solve the contradiction between resource shortage and sustainable development on a certain basis, improve the effective utilization rate of energy and improve the living environment, and become one of the preferred ways for people to pursue sustainable development [10]. It was a better choice to heat brood with air energy heat pump, which could meet the requirements of energy saving and consumption reduction in breeding industry.

\section{Project fund}

This work was supported by Chinese National Agriculture Research System (CARS-41-G04), Key Technology Support Program of Sichuan Province (2019YFN0009, 2021YFYZ0031, 21ZDYF2278), and Sichuan Provincial Finance Operation Special Project (SASA2020CZYX002, SASA2020CZYX007).

\section{References:}

1. Liu Xiaohong. (2017) The main causes and countermeasures of low survival rate of chicken brood. Veterinary Guide,20:235-238.

2. Qiu Xiaolin. (2010) Introduction of chicken raising equipment. Farming technical advisor,7:45.

3. Jin Chaomin. (2017) Application research of air energy heat pump heat pump heating. Science and 
Technology Investment in China,35:324.

4. Yunsong Gu, Fumei Zhou, Dinghua Li, et al. (2017) Comparison of baking effect between air energy heat pump and coal burning intensive baking house. Journal of Zhejiang Agricultural Sciences, 58(11):2039-2041,2045.

5. Wang, X.N., Wang, S.P., Wang, X.Z. (2008) A mathematical model of NH3 concentration variation in chicken coop under the effect of fan ventilation. Journal of Anhui Agricultural Sciences,36(14):5695-5695,5746.

6. Zheng Shuli. (2009) Environmental control of cage laying hens in summer. China Poultry Industry Guide,26(6):12-13.

7. Yin C H, Sheng Z G, Zhang A M, et al. (2017) gosling carbon monoxide Diagnosis and treatment of poisoning. Science and Technology Information of Animal Husbandry and Veterinary, 10:90.

8. Shao, X.M. (2009) Prevention and control of carbon monoxide poisoning in chickens. Animal Husbandry and Feed Science, 30(10):135.

9. Lei Mingde. (2016) Effects of temperature and humidity on brood breeding. Chinese Animal Husbandry and Veterinary Abstracts, 32(5):73-74.

10. Zhang Jian. (2015) Application prospect of air energy heat pump. Business Review, 8:62-62,64. 